20

\title{
Идентификация и счет эритроцитов нативной донорской крови человека методом цифровой оптической микроскопии с использованием спектрально фильтрованного освещения
}

\author{
(С) В.А. Дубровский ${ }^{1}$, И.В. Забенков ${ }^{1}$, Е.П. Карпочева ${ }^{2}$, С.О. Торбин $^{1}$ \\ ${ }^{1}$ Саратовский государственный медицинский университет им. В.И. Разумовского, \\ 410012 Саратов, Россия \\ ${ }^{2}$ Саратовская областная станция переливания крови, \\ 410033 Саратов, Россия \\ ฯ e-mail: zabenkoviv@yandex.ru
}

Поступила в редакцию 29.07.2020 г.

В окончательной редакции 13.11.2020 г.

Принята к публикации 18.11.2020 г.

\begin{abstract}
Изучена возможность идентификации и счета эритроцитов нативной донорской крови на основе статической, непроточной цифровой оптической микроскопии. Объектом исследования являлась цельная донорская кровь, разбавленная физиологическим раствором и размещенная в камере Горяева. Образец изучался в проходящем свете с помощью цифрового оптического микроскопа Люмам Р-8, снабженного камерой Basler acA1920-40um. С целью идентификации эритроцитов по спектральному признаку были получены два набора микрофотографий по 20 штук. В первом наборе в осветительном канале микроскопа оптический светофильтр отсутствовал, а во втором применялся интерференционный светофильтр на длину волны $420 \mathrm{~nm}$ с шириной полосы пропускания $10 \mathrm{~nm}$. Характеристики интерференционного светофильтра выбирались из соображений близости к полосе Соре гемоглобина эритроцитов для получения наилучшего контраста фотоизображений. С помощью программного инструментария OpenCV была разработана методика автоматизированного анализа микрофотографий, позволяющая распознавать эритроциты и осуществлять их подсчет. Результаты программного счета эритроцитов сравнивались с числом эритроцитов, подсчитанным вручную. Установлено, что при таком компьютерном подходе доля распознанных эритроцитов составляет в среднем 97-98\%.
\end{abstract}

Ключевые слова: идентификация эритроцитов, счет эритроцитов, оптическая микроскопия, автоматизированный анализ.

DOI: $10.21883 /$ OS.2021.03.50660.208-20

\section{Введение}

\section{Анализ крови с помощью оптической микроскопии при непосредственном визуальном наблюдении препарата в окуляре или на экране монитора}

Общий анализ крови (ОАК) является одним из самых частых лабораторных медицинских тестов, позволяющих выявлять такие патологии крови, как анемия, эритроцитоз, лейкоцитоз, лейкопения и другие. При исследовании таких показателей, как число эритроцитов и лейкоцитов в единице объема, лейкоцитарной формулы, описании морфологии клеток крови, традиционно используют методы оптической микроскопии. При этом для определения одних параметров форменных элементов крови используется препарат в виде раствора нативной крови, помещенный в камеру Горяева, а для других мазок крови, окрашенный по Романовскому-Гимзе. Так, микроскопический анализ нативной крови позволяет определить концентрацию форменных элементов крови и морфологические особенности эритроцитов. С другой стороны, изучение окрашенного мазка крови используют для определения лейкоцитарной формулы.

Однако традиционные микроскопические методы ОАК являются довольно трудо- и времязатратными и не обладают высокой точностью. Например, погрешность при определении содержания эритроцитов с использованием камеры Горяева при „ручном подсчете“ составляет порядка $10-15 \%$ [1].

\section{Проточные гематологические анализаторы}

Изобретение проточного гематологического анализатора в 1956 г. позволило в значительной мере снять нагрузку с врачей-гематологов, увеличить число обрабатываемых проб, а также повысить точность и воспроизводимость получаемых результатов. Современные гематологические автоанализаторы позволяют выполнять измерения концентрации клеток крови с погрешностью $1-3 \%$, при этом производительность таких устройств варьирует от 30 до 120 проб крови в час [2]. Отметим, что анализируемая проба в таких приборах представляет собой либо цельную нативную кровь, стабилизированную ЭДТА, либо ее раствор. 
Подсчет клеток в проточных гемоанализаторах осуществляется, как правило, кондуктометрическим способом, а использование оптических методов позволяет дифференцировать лейкоциты на пять групп, а также определять концентрацию гемоглобина. Использование широкого комплекса физических методов позволило наряду с обычными гематологическими показателями (концентрация эритроцитов, лейкоцитов, гемоглобина) определять и другие важные показатели, такие как MCV, $\mathrm{MCH}, \mathrm{MCHC}, \mathrm{RDW}$ и другие, что расширило диагностические возможности выполняемого анализа [3-5].

Тем не менее важно отметить, что использование кондуктометрических и оптических методов позволяет лишь косвенно определять указанные параметры крови. К недостаткам таких анализаторов относится сложность их технического обслуживания и высокие стоимостные характеристики: цена прибора, стоимость реагентов и технического обслуживания, а также ремонта.

\section{Автоматизация статической цифровой микроскопии}

Развитие компьютерной техники наряду с ростом ее вычислительной мощности и совершенствованием когнитивных алгоритмов анализа изображений позволило возобновить интерес к статическим микроскопическим методам анализа крови и созданию гематологических анализаторов нового типа, работающих на базе цифровых оптических микроскопов. Так, например, российская компания „Мекос“ выпускает серийно сканеранализатор „МЕСО-НЕМО“, который позволяет автоматизировать рутинную методику микроскопического анализа морфологии клеток крови, дополняя ее средствами углубленного анализа [6]. Однако во всех подобного рода анализаторах изучается не раствор крови, а мазок, что не позволяет определять концентрацию форменных элементов крови. Таким образом, автоматизированные гематологические анализаторы на базе микроскопов лишь дополняют собой классические проточные гемоанализаторы, но не заменяют их.

Тем не менее появилось большое количество работ, посвященных автоматизированному подсчету и анализу форменных элементов крови на основе методов цифровой микроскопии и алгоритмов искусственного зрения. Развитие таких автоматизированных микроскопических комплексов в качестве гематологических анализаторов является, по нашему мнению, перспективным, поскольку позволит перейти от технической сложности проточных гемоанализаторов к сложности компьютерных методов обработки микрофотографий [7,8]. Другим важным достоинством микроскопических статических гемоанализаторов является возможность сохранять первичные данные о препарате в виде виртуальных слайдов. При этом появляется возможность отложенного анализа этих данных с использованием новых когнитивных алгоритмов, а также визуального контроля со стороны врачагематолога.
Однако в большинстве работ, посвященных исследования форменных элементов крови методами статической цифровой микроскопии, в качестве препарата выступает не раствор нативной крови, а окрашенные мазки [9-14]. Такой подход позволяет определять лейкоцитарную формулу, а также количественное соотношение между форменными элементами различных типов, но не позволяет определять их концентрацию. Отметим, что доля идентифицированных эритроцитов в этих работах достигает 97\% [13], а лейкоцитов 98\% [15]. Представляется важным отметить, что количество статей, посвященных подсчету эритроцитов в нативной крови, невелико, помимо $[16,20]$ нам удалось познакомиться лишь с $[17,18]$. Это означает, что лишь немногие работы, посвященные автоматизированному анализу крови, дают возможность определять концентрацию форменных элементов.

Анализ показывает, что большинство работ, посвященных автоматизированной идентификации, подсчету и анализу формы клеток крови на микрофотографиях, используют их морфологические признаки. [7,8]. При этом в отличие от гематологических анализаторов в этих работах не используются спектральные свойства форменных элементов.

Целью настоящей работы являлась разработка метода идентификации и автоматизированного подсчета эритроцитов в образцах раствора нативной донорской крови на основе статической цифровой микроскопии с использованием спектральных свойств эритроцитов.

\section{1. Экспериментальная установка и пробоподготовка}

В качестве объектов исследования выступали два образца цельной донорской крови, разбавленные физиологическим раствором. С помощью серийного гемоанализатора Sysmex XS 1000i для используемых образцов крови были определены соответственно содержание гемоглобина (157 и $120 \mathrm{~g} / \mathrm{L})$, концентрация эритроцитов $\left(5.25 \cdot 10^{12}\right.$ и $\left.4.47 \cdot 10^{12} \mathrm{~L}^{-1}\right)$, а также уровень гематокрита (44.0 и 34.9\%). Первый образец (обозначим S1) разбавлялся физиологическим раствором в 100, 200, 300 и 400 раз, а второй образец (обозначим S2) в 100 и 400 раз. Для микроскопического анализа капля полученного раствора объемом $20 \mu \mathrm{L}$ помещалась в камеру Горяева под покровное стекло и выдерживалась одну минуту, чтобы все форменные элементы успели осесть на дно. Все образцы изучались в проходящем свете с помощью цифрового оптического микроскопа Люмам Р-8, снабженного монохромной камерой Basler acA1920-40um (рис. 1). Разрешение этой камеры составляет $1920 \times 1200$ пикселей, а глубина цвета 12 bit. Важной особенностью этой камеры является линейность зависимости регистрируемого сигнала (выраженного в цифровых единицах) от интенсивности падающего на фотоматрицу света. 


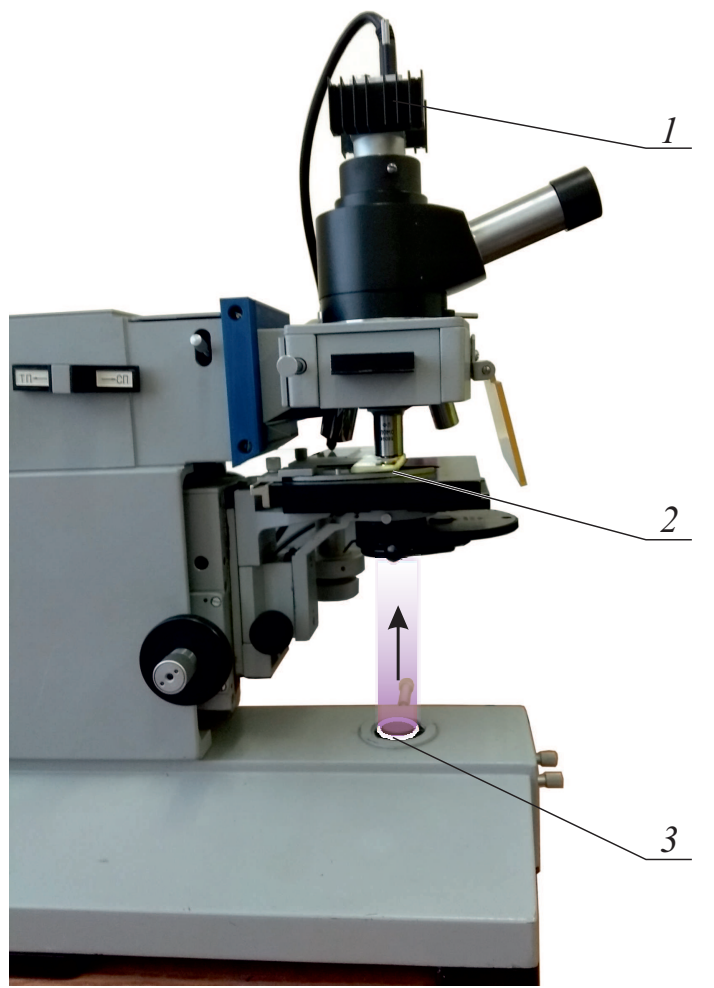

Рис. 1. Схема экспериментальной установки: 1 - цифровая монохромная камера Basler acA1920-40um, 2 - камера Горяева с раствором нативной донорской крови, 3 - интерференционный светофильтр.

Для получения микрофотографий использовался объектив с коэффициентом увеличения $40 \times$ и числовой апертурой 0.65 . Разрешающая способность фотографий при этом составила $6900 \mathrm{pel} / \mathrm{mm}$.

При микроскопическом изучении обоих образцов для каждой области микропрепарата снималось по две фотографии. Однако для образца S1 регистрация одной из фотографий осуществлялась без светофильтра в осветительном канале микроскопа, а при регистрации другой применялся интерференционный светофильтр с максимумом пропускания $31 \%$ на длине волны $416 \mathrm{~nm}$ и шириной полосы $10 \mathrm{~nm}$ (обозначим его IF416). Кроме основной полосы пропускания этот светофильтр имел еще и побочную полосу шириной $10 \mathrm{~nm}$ с максимумом пропускания $25 \%$ на длине волны $820 \mathrm{~nm}$. Интерференционный светофильтр выбирался исходя из соображений максимальной близости его основной полосы пропускания к максимуму поглощения света оксигемоглобином - полосе Соре $(415 \mathrm{~nm}$, кривая 1 на рис. 2). С целью облегчения последующей программной обработки фотографий уровень яркости источника выбирался таким, чтобы максимальный уровень сигнала не превышал уровень насыщения камеры (4096).

Поскольку светофильтр IF416 поглощал 99.5\% световой энергии, то полученное с его помощью изображение было настолько темным, что визуально воспринималось как черное поле. При этом для анализа оказывалось доступно лишь $0.5 \%$ от сигнала, регистрируемого в отсутствие светофильтра. Для того чтобы привести уровни яркости обеих фотографий к одному порядку величины, было принято решение для образца S2 использовать поочередно два интерференционных светофильтра вместо одного. Так, для получения одной микрофотографии выбранного участка микропрепарата по-прежнему применялся светофильтр IF416, а регистрация второй осуществлялась с использованием интерференционного светофильтра с максимумом пропускания $38.4 \%$ на длине волны $620 \mathrm{~nm}$ и шириной полосы $14 \mathrm{~nm}$ (обозначим его IF620, рис. 2). Этот светофильтр был выбран потому, что на длине волны $620 \mathrm{~nm}$ поглощение света гемоглобином почти отсутствует. Заметим, что светофильтр IF620 также имел побочную полосу шириной $14 \mathrm{~nm}$ с максимумом пропускания $26 \%$ на длине волны $924 \mathrm{~nm}$. Чтобы исключить из светового потока побочные полосы пропускания светофильтров IF416 и IF620 (820 и $924 \mathrm{~nm}$ ), в осветительный канал микроскопа дополнительно водился широкополосный светофильтр СЗС-23.

Для того чтобы привести яркость фотографий, получаемых с каждым из светофильтров, к уровню, приемлемому для визуального наблюдения, регулятор источника света микроскопа устанавливался из среднего положения в максимальное. Кроме того, в 10 раз было увеличено время выдержки камеры - с 3 до $30 \mathrm{~ms}$.

Важно отметить, что в двух сериях экспериментов без светофильтра IF416, а также со светофильтрами IF620/IF416 - использовались два разных образца крови.

\section{2. Принцип идентификации эритроцитов}

При визуальном наблюдении образцов крови посредством микроскопа идентификация эритроцитов осу-

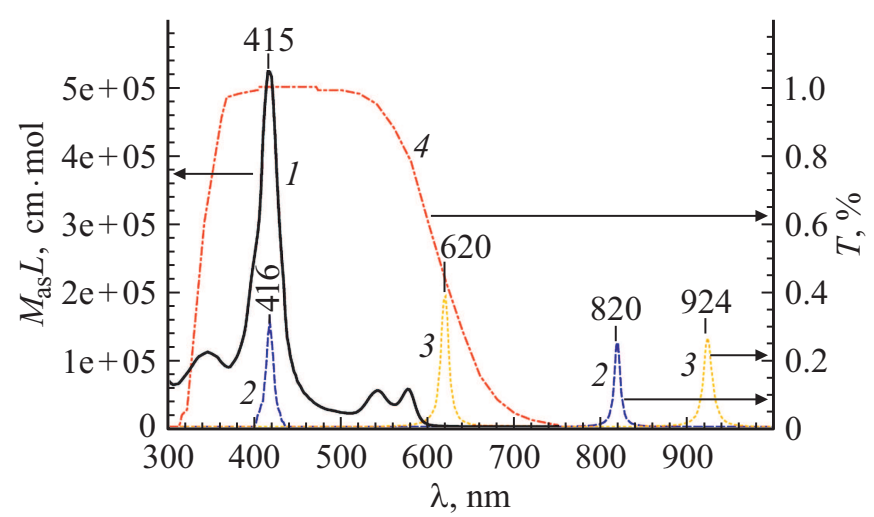

Рис. 2. Спектральные характеристики гемоглобина и светофильтров: 1 - молярный коэффициент поглощения оксигемоглобина, 2 - спектр пропускания светофильтра IF416, 3 - спектр пропускания светофильтра IF620, 4 - спектр пропускания светофильтра С 3 - 23. 
ществляется путем а) сравнения яркости их изображений по отношению к яркости фона, б) анализа формы и структуры клетки. Рассмотрим возможность идентификации эритроцитов на основе сравнения упомянутых яркостей, но морфологические характеристики эритроцитов заменим на спектральные. В силу природной окрашенности эритроцитов представляется возможным спектрально достигнуть высокого уровня отличия яркости изображения эритроцитов от яркости фона. Более того, столь высокое отличие оказывается специфическим именно по отношению к эритроцитам. Эти принципы положим в основу идентификации эритроцитов с последующим их счетом.

\section{1. Поднятие порога разрешения эритроцитов}

Видность форменных элементов крови при наблюдении их с помощью светового микроскопа обеспечивается прежде всего рассеянием проходящего через них светового потока. Тем не менее в отличие от лейкоцитов и тромбоцитов, которые в видимой области спектра практически прозрачны, эритроциты содержат примерно 1/3 массовой доли гемоглобина, имеющего две полосы поглощения в видимой области спектра. В зависимости от физиологической формы гемоглобина варьирует и его спектр. Так, на рис. 2 (кривая 1) [19] представлен спектр оксигемоглобина, который имеет две полосы поглощения в видимой области спектра. Одна полоса поглощения (полоса Cope) имеет максимум на длине волны $415 \mathrm{~nm}$, а другая находится в зеленой области спектра в диапазоне 520-590 nm.

Поскольку интегральное по спектру поглощение света одиночными эритроцитами невелико, то при визуальном наблюдении это поглощение обнаружить затруднительно на фоне значительного перераспределения интенсивности в плоскости изображения, вызванного рассеянием на них. Кроме того, невозможно оценить вклад поглощения количественно, используя лишь визуальное наблюдение микропрепарата. Однако современные цифровые камеры, особенно с линейной характеристикой зависимости цифрового сигнала от интенсивности светового потока, могут использоваться для количественного определения распределения интенсивности светового потока в плоскости изображения.

В настоящей работе для идентификации эритроцитов используется эффект поглощения световой энергии гемоглобином, входящим в их состав. Идея заключается в следующем. Если сфотографировать изображение микропрепарата раствора нативной донорской крови, то на полученном изображении будут участки фона, а также участки, содержащие изображения эритроцитов, лейкоцитов и тромбоцитов. Яркость фона обозначим $B_{\mathrm{bg}}$ (background $B_{\mathrm{bg}}$ ), а среднюю яркость фрагментов c эритроцитами - $B_{\mathrm{RBC}}$. Отношение этих яркостей $B_{\mathrm{bg}} / B_{\mathrm{RBC}}$ определяется поглощением световой энергии гемоглобином. Однако гемоглобин поглощает световую энергию спектрально неравномерно. В результате, если световой поток, падающий на образец, подвергнуть спектральной фильтрации так, чтобы остался только диапазон частот, соответствующий полосе поглощения гемоглобина, то отношение $B_{\text {bg_f }} / B_{\text {RBC_f }}$ (индекс $\mathrm{f}-$ filtered) должно оказаться больше, чем аналогичное соотношение, полученной без светофильтра:

$$
\frac{B_{\mathrm{bg} \_\mathrm{f}}}{B_{\mathrm{RBC}_{-} \mathrm{f}}}>\frac{B_{\mathrm{bg}}}{B_{\mathrm{RBC}}} .
$$

Последнее неравенство можно переписать в эквивалентной форме

$$
\frac{B_{\mathrm{RBC}}}{B_{\mathrm{RBC} \_\mathrm{f}}}>\frac{B_{\mathrm{bg}}}{B_{\mathrm{bg} \__{-} \mathrm{f}}} .
$$

Если ввести граничный параметр $K_{1}$ такой, что для него будет выполняться двойное неравенство

$$
\frac{B_{\mathrm{RBC}}}{B_{\mathrm{RBC} \_\mathrm{f}}}>K_{1}>\frac{B_{\mathrm{bg}}}{B_{\mathrm{bg}_{-} \mathrm{f}}},
$$

то его можно будет использовать в качестве индикатора принадлежности пикселя либо фону, либо эритроциту.

Таким образом, в предлагаемом методе идентификации эритроцитов необходимо делать по две фотографии каждой области микропрепарата. Одна регистрируется без светофильтра (Img), а другая - с использованием светофильтра $\left(\operatorname{Img}_{\mathrm{f}}\right)$, имеющего полосу пропускания, соответствующую полосе поглощения гемоглобина. Затем для каждого пикселя $(i, j)$ необходимо находить отношение яркостей $\operatorname{rel}(i, j)=\operatorname{Img}(i, j) / \operatorname{Img}_{\mathrm{f}}(i, j)$. Полученный в результате этого массив rel будем называть относительным изображением. Если для очередного пикселя соотношение $r(i, j) \geq K_{1}$, то этот пиксель принадлежит эритроциту, а если наоборот, то он соответствует фону или иному форменному элементу крови.

Использование двух режимов сьемки микропрепарата крови, а также соотношения (3) для идентификации эритроцитов решает два вопроса. Во-первых, применение отношения яркостей пикселей $\operatorname{Img}(i, j) / \operatorname{Img}_{\mathrm{f}}(i, j)$ вместо абсолютных единиц яркости позволяет избежать зависимости параметра $K_{1}$ от яркости источника освещения. Это означает, что при реализации описанного метода источник освещения не нужно юстировать по яркости. Заметим, однако, что отношение $\operatorname{Img}(i, j) / \operatorname{Img}_{\mathrm{f}}(i, j)$ зависит не только от пропускания светофильтра, но и от спектра источника освещения. В силу этого при смене источника освещения на источник с другим спектром необходимо корректировать и параметр $K_{1}$.

Другая задача, которую решает использование двух режимов сьемки микропрепарата крови, это специфичность описанного метода идентификации эритроцитов к гемоглобину. Так, если использовать только фотоизображение, полученное без светофильтра, то для каждого пикселя, более темного относительно фона, будет неясно, вызвано это потемнение перераспределением яркости из-за рассеяния (тромбоцитом, лейкоцитом, артефактом) или поглощением гемоглобина. Кроме того, 


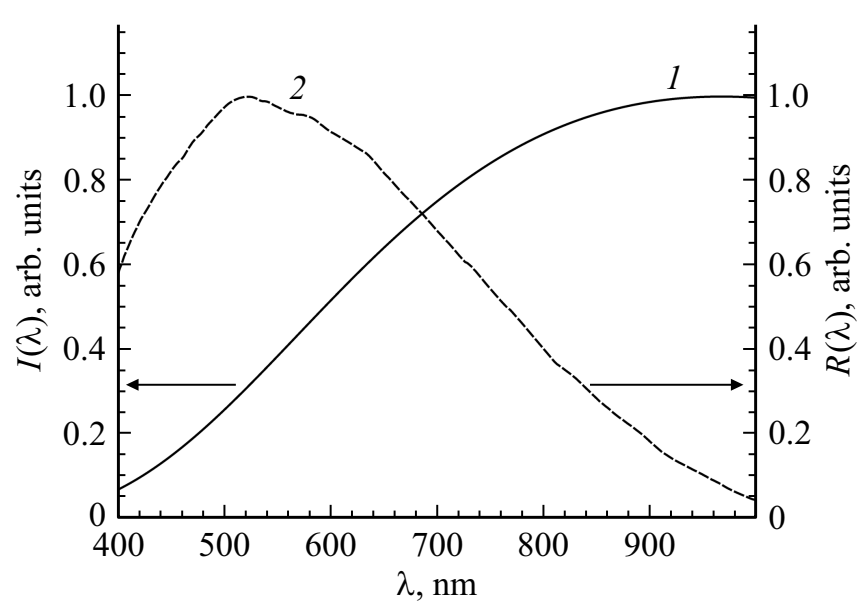

Рис. 3. Спектр галогеновой лампы КГМ9-70 (рассчитан по формуле Планка при цветовой температуре $3000 \mathrm{~K})(1)$, спектральная характеристика чувствительности камеры Basler acA1920-40um (2) (документация камеры).

поглощение света гемоглобином отдельного эритроцита относительно невелико (что будет показано ниже), так что отделить поглощение от рассеяния по одной фотографии без светофильтра не представляется возможным. С другой стороны, если для идентификации эритроцитов использовать только фотографию, полученную со светофильтром, то для более темных относительно фона пикселей будет по-прежнему не ясно, вызвано это потемнение поглощением света гемоглобином эритроцитов в области полосы Соре или же неким артефактом, имеющим широкий спектр поглощения.

\section{2. Оценка порогового условия разрешения регистрируемых эритроцитов}

Для того чтобы количественно оценить поглощение эритроцитов в двух режимах сьемки при регистрации изображения с помощью цифровой камеры, рассмотрим упрощенную модель эритроцита в виде диска толщиной $d_{\mathrm{RBC}}=1.97 \mu \mathrm{m}$. Это значение примерно соответствует толщине нормоцита среднего диаметра и объема. Положим также, что ослабление светового потока таким диском вызвано только поглощением света, происходящим по закону Бугера.

Яркость фрагмента изображения, соответствующая фону, может быть найдена с помощью соотношения

$$
B_{\mathrm{bg}}=\int_{400}^{1000} I(\lambda) R(\lambda) d \lambda
$$

где $I(\lambda)$ - спектр источника освещения в микроскопе, в качестве которого используется галогеновая лампа КГМ9-70, а $R(\lambda)$ - спектральная чувствительность матрицы цифровой камеры Basler acA1920-40um. Соответствующие спектры представлены на рис. 3 .

Средняя яркость фрагмента изображения, соответствующая эритроциту, может быть найдена с помощью выражения

$$
B_{\mathrm{RBC}}=\int_{400}^{1000} I(\lambda) R(\lambda) \exp \left(-\mu_{\mathrm{RBC}}(\lambda) d_{\mathrm{RBC}}\right) d \lambda,
$$

где $\mu_{\mathrm{RBC}}(\lambda)-$ спектральная зависимость коэффициента поглощения эритроцита, которая в свою очередь может быть найдена с помощью модифицированного соотношения [19]

$$
\mu_{\mathrm{RBC}}=\frac{2.303 M_{a} H G B}{64500 H G T},
$$

где $M_{a}$ - молярный коэффициент поглощения гемоглобина $[\mathrm{L} /(\mathrm{mol} \cdot \mathrm{cm})]$ (рис. 2, кривая 1$), H G B$ - содержание гемоглобина $[\mathrm{g} / \mathrm{L}], H G T-$ уровень гематокрита в образце донорской крови.

Для того чтобы определить содержит данный фрагмент изображения эритроцит или фон в соответствии с выражениями (1)-(3), необходимо также оценить значения яркостей в условиях введения в оптический канал светофильтра. Если свет от источника будет проходить через светофильтр IF416, то выражение для яркости фона модифицируется введением в формулу (4) спектральной зависимости пропускания светофильтра IF416 $\left(T_{\mathrm{IF} 416}(\lambda)\right.$ - рис. 2 , кривая 2$)$ и примет вид

$$
B_{\text {bg_416 }}=\int_{400}^{1000} I(\lambda) T_{\mathrm{IF} 416}(\lambda) R(\lambda) d \lambda .
$$

Среднюю яркость фрагмента изображения с эритроцитом при этом можно оценить с помощью выражения

$$
\begin{array}{rl}
B_{\mathrm{RBC} \_416}=\int_{400}^{1000} & I(\lambda) T_{\mathrm{IF} 416}(\lambda) R(\lambda) \\
& \times \exp \left(-\mu_{\mathrm{RBC}}(\lambda) d_{\mathrm{RBC}}\right) d \lambda .
\end{array}
$$

Для вычислений по формулам (4)-(8) были использованы параметры крови первого образца и спектр поглощения оксигемоглобина. Полученные данные приведены во втором и третьем столбцах табл. 1. Анализируя эти значения, можно сделать следующие выводы. Во-первых, при внесении в осветительную систему микроскопа интерференционного светофильтра IF416 оставшаяся яркость изображения составит всего $0.58-0.66 \%$ от яркости изображения без светофильтра. Это означает, что при использовании камеры с глубиной цвета 8 bit будет затруднительно получить достоверное изображение при переходе от режима без светофильтра к режиму со светофильтром IF416. Во-вторых, в отсутствие светофильтра при переходе от зоны фона к зоне эритроцита яркость уменьшается на $3 \%$ (табл. 1). В то же время со светофильтром аналогичный параметр составит $14 \%$. При этом отношение яркостей области фона $B_{\mathrm{bg}} / B_{\mathrm{bg} 416}$ составит 152, а аналогичное соотношение для области эритроцита $B_{\mathrm{RBC}} / B_{\mathrm{RBC} \_416}$ составит 171 . Отличие последних значений составляет всего около $12 \%$.

С одной стороны, такое изменение уже можно пытаться использовать для идентификации эритроцитов. 
Таблица 1. Расчетные значения (arb. units) относительной яркости фрагментов изображений (формулы (10)-(13)), содержащие фон и эритроциты: полученные без светофильтра (столбец 2), со светофильтром IF416 (столбец 3), а также с парами светофильтров IF416+C3C-23 (столбец 4) и IF620+C3C-23 (столбец 5); в столбцах 6, 7 приведены отношения указанных яркостей $($ в \%)

\begin{tabular}{l|c|c|c|c|c|c}
\hline $\begin{array}{l}\text { Фрагмент } \\
\text { изображения }\end{array}$ & $\begin{array}{c}\text { Без } \\
\text { фильтра }\end{array}$ & IF416 & $\begin{array}{c}\text { IF416+ } \\
\text { С3C-23 }\end{array}$ & $\begin{array}{c}\text { IF620+ } \\
\text { С3С-23 }\end{array}$ & $\begin{array}{c}\text { IF416/ } \\
\text { без фильтра, \% }\end{array}$ & $\begin{array}{c}\text { (IF416+C3C-23)/ } \\
\text { (IF620+C3C-23), \% }\end{array}$ \\
\hline \multicolumn{1}{c|}{1} & 2 & 3 & 4 & 5 & 6 & 7 \\
\hline Фон & 0.30954 & 0.00203 & 0.00041 & 0.00218 & 0.66 & 18.81 \\
RBC & 0.30010 & 0.00175 & 0.00013 & 0.00216 & 0.58 & 6.02 \\
RBC/фон & 0.97 & 0.86 & 0.32 & 0.99 & &
\end{tabular}

При этом граничное значение параметра $K_{1}$ в рамках этой модели эксперимента и вычислений должно быть $152<K_{1}<171$. Однако с другой стороны, это изменение соотношения является малым как из-за наличия поглощения гемоглобина в режиме без светофильтра, так и из-за дополнительного пропускания светофильтра IF416 в области прозрачности гемоглобина $(80 \mathrm{~nm})$.

\section{3. Усиление спектрального разрешения эритроцитов}

Усилить описанный эффект спектрального различения фрагментов микрофотографий, содержащих фон и эритроциты, можно следующим образом. Во-первых, нужно исключить влияние побочной полосы пропускания светофильтра IF416 путем использования вместе с ним светофильтра СЗС-23, спектр пропускания которого $\left(T_{\mathrm{C} 3 \mathrm{C} 23}(\lambda)\right)$ представлен на рис. 2 (кривая 4$)$. Кроме того, вместо регистрации фотографии без светофильтра, которая содержит информацию о поглощении эритроцитов, можно осуществлять ее регистрацию с применением интерференционного светофильтра, например IF620. Поскольку этот светофильтр имеет полосу пропускания с максимумом на длине волны $620 \mathrm{~nm}$, на которой гемоглобин практически не поглощает свет, то зарегистрированный сигнал будет определяться только рассеянием света на эритроцитах практически без его поглощения. При этом средняя яркость фрагмента фотоизображения с эритроцитом практически сравняется с таковой для фона, как результат неравенства (1)-(3) усилятся, а значит, должна возрасти надежность идентификации эритроцитов.

Кроме того, использование светофильтра IF620 совместно со светофильтром СЗС-23 позволяет привести уровень яркости изображения к значениям, получаемым при использовании пары светофильтров IF416+C3C-23. Естественно также, что для данного варианта методики будет свое значение граничного параметра $K_{2}$, удовлетворяющего неравенству

$$
\frac{B_{\mathrm{RBC} \_620 \_23}}{B_{\mathrm{RBC} \_416 \_23}}>K_{2}>\frac{B_{\text {bg } \_620 \_23}}{B_{\text {bg } \_416 \_23}},
$$

где $B$ RBC_416_23 и $B$ bg_416_23 - средние значения яркостей изображений, полученных с помощью пары светофильтров IF416+C3C-23 в области эритроцита и фона соответственно. $B_{\mathrm{RBC} \_620 \_23}$ и $B_{\text {bg_620_23 }}$ - аналогичные значения яркостей, полученные с помощью светофильтров IF620+C3C-23.

В итоге модифицированный вариант методики идентификации эритроцитов будет выглядеть следующим образом. Для каждой области микропрепарата необходимо делать по две фотографии. Одна регистрируется с использованием светофильтров IF416+C3C-23 $\left(\mathrm{Img}_{416 \_23}\right)$, а другая с использованием светофильтров IF620+C3C-23 (Img (20_23 $\left._{2}\right)$. Затем для каждого пикселя $(i, j)$ необходимо находить отношение яркостей $\operatorname{rel}(i, j)=\operatorname{Img}_{620 \_23}(i, j) / \operatorname{Img}_{416 \_23}(i, j)$. Если для очередного пикселя соотношение $\operatorname{rel}(i, j) \geq K_{2}$, то этот пиксель является частью эритроцита, а если наоборот, то он принадлежит фону или иному форменному элементу крови.

Чтобы оценить относительную эффективность модифицированной методики идентификации эритроцитов, вычислим соответствующие значения яркостей $B_{\mathrm{RBC} \_416 \_23}$ и $B_{\text {bg_416_23, }}$, а также $B_{\mathrm{RBC} \_620 \_23}$ и $B$ bg_620_23, используя описанную выше модель эритроцита. Яркости зон микрофотографий с фоном, а также с эритроцитом, получаемых с парой светофильтров IF416+C3C-23, можно найти с помощью выражений

$$
\begin{array}{r}
B_{\text {bg } \_416 \_23}=\int_{400}^{1000} I(\lambda) T_{\mathrm{IF} 416}(\lambda) T_{\mathrm{SZS} 23}(\lambda) R(\lambda) d \lambda, \\
B_{\mathrm{RBC} \_416 \_23}=\int_{400}^{1000} I(\lambda) T_{\mathrm{IF} 416}(\lambda) T_{\mathrm{SZS} 23}(\lambda) R(\lambda) \\
\times \exp \left(-\mu_{\mathrm{RBC}}(\lambda) d_{\mathrm{RBC}}\right) d \lambda,
\end{array}
$$

где $T_{\mathrm{SZS} 23}(\lambda)$ - спектральная характеристика пропускания светофильтра С 3 -23. В то же время яркости участков микрофотографий с фоном и с эритроцитами, получаемые со светофильтрами IF620+C3C-23, можно оценить с помощью аналогичных выражений:

$$
B_{\text {bg } \_620 \_23}=\int_{400}^{1000} I(\lambda) T_{\mathrm{IF} 620}(\lambda) T_{\mathrm{SZS} 23}(\lambda) R(\lambda) d \lambda,
$$




$$
\begin{array}{rl}
B_{\mathrm{RBC} \_620 \_23}=\int_{400}^{1000} & I(\lambda) T_{\mathrm{IF} 620}(\lambda) T_{\mathrm{SZS} 23}(\lambda) R(\lambda) \\
& \times \exp \left(-\mu_{\mathrm{RBC}}(\lambda) d_{\mathrm{RBC}}\right) d \lambda,
\end{array}
$$

где $T_{\mathrm{IF620}}(\lambda)$ - спектр пропускания светофильтра IF620 (рис. 2, кривая 3).

Для вычислений по формулам (6), (10)-(13) были использованы параметры крови первого образца и спектр поглощения оксигемоглобина. Результаты вычислений приведены в столбцах 4 и 5 табл. 1. Как можно ви-

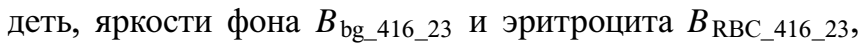
получаемые со светофильтрами IF416 и СЗС-23, составляют около $19 \%$ и $6 \%$ от соответствующих фоновых

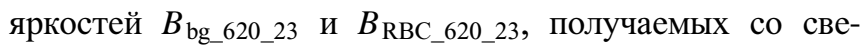
тофильтрами IF620 и СЗС-23. Это означает, что эти яркости имеют один порядок величины, что позволяет использовать для регистрации обоих изображений камеру с глубиной цвета 8 bit. Кроме того, отношение яркостей фона $B_{\text {bg_620_23 }} / B_{\text {bg_416_23 }}$ будет примерно равно $0.00218 / 0.00041 \approx 5$, а аналогичное соотношение $B_{\mathrm{RBC} \_620 \_23} / B_{\mathrm{RBC} \_416 \_23}$ для фрагментов изображения, содержащих эритроцит, уже будет примерно 16. Отличие между последними значениями составляет внушительные $68 \%$.

Полученный результат свидетельствует о возможности надежной идентификации эритроцитов по их поглощению путем регистрации и дальнейшей обработки пары фотографий, первая из которых получается при использовании диапазона длин волн прозрачности гемоглобина, а вторая - при использовании диапазона длин волн в области полосы Cope.

\section{3. Результаты экспериментов}

Для образца крови S1 было сделано по 10 пар фотографий для каждого разведения $(1: 100,1: 200,1: 300$, 1:400) по методике, описанной в разд. 2. На рис. 4 представлены типичные микрофотографии, полученные без светофильтра $(a)$, а также со светофильтром IF416 в канале освещения микроскопа $(b)$. Поскольку оригинальная фотография, полученная в присутствии светофильтра, не позволяет различить какие-либо объекты, то мы построили по этим данным график оттенков яркости (colormash) с соответствующей шкалой.

Для того чтобы найти оптимальное значение граничного параметра $K_{1}$, необходимого для идентификации эритроцитов, для каждой пары фотографий были определены средние яркости 50 фрагментов фона, а также 50 участков, содержащих эритроциты. Среднее значение яркости в области фона на фотографиях, полученных без светофильтра, оказалось равным 1751 и 5 - на фотографиях, полученных со светофильтром IF416. Аналогичное значение яркости в областях эритроцитов на фотографиях, полученных без светофильтра, составило 1624 и 2 - на фотографиях, полученных со светофильтром IF416. Полученные из эксперимента средние значения
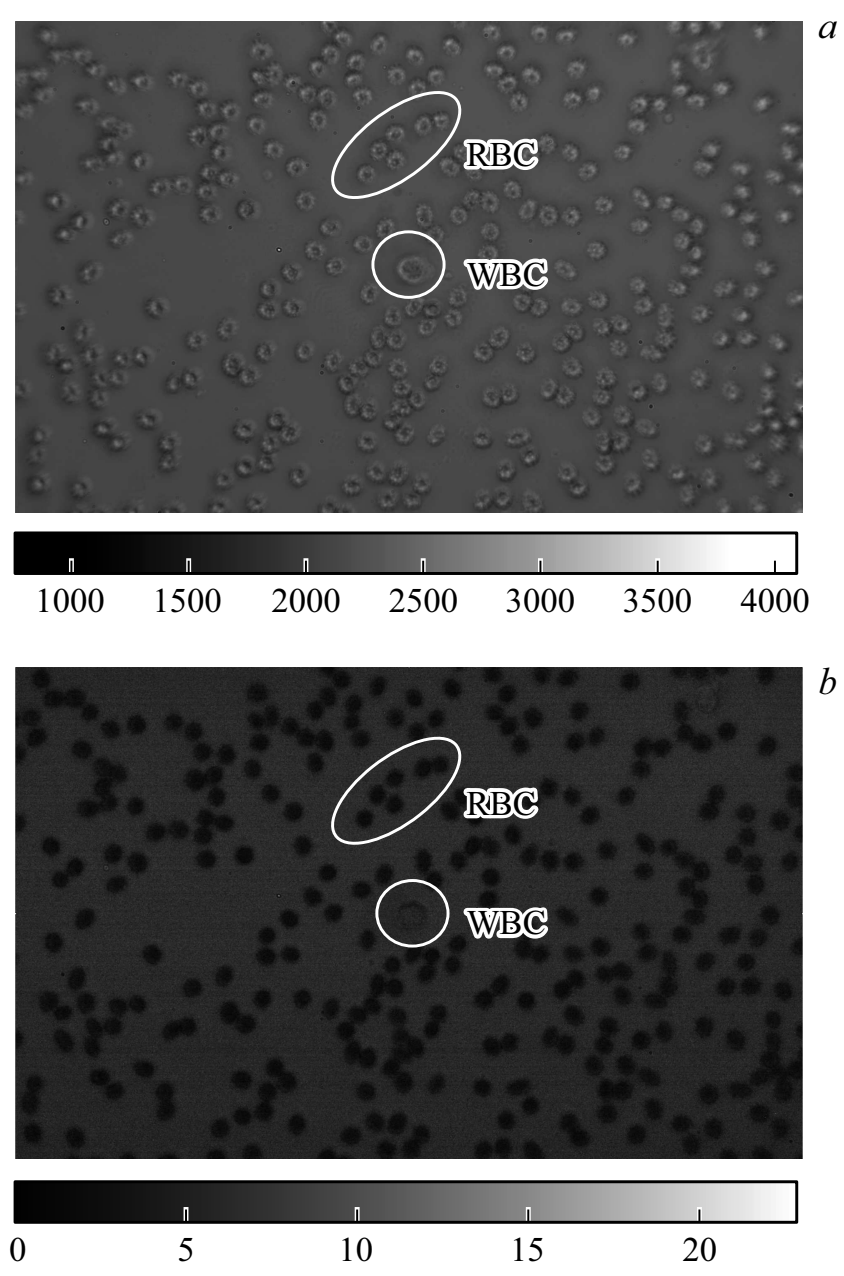

Рис. 4. Изображения микропрепарата раствора нативной донорской крови $(\mathrm{S} 1)$ в физиологическом растворе (1:100), полученные без светофильтра $(a)$, а также со светофильтром IF416 в канале освещения $(b)$.

яркостей областей фотографий размещены в столбцах 2 и 3 табл. 2.

На рис. 5, $a$ представлены гистограммы распределения отношений яркостей фона $B_{\mathrm{bg}} / B_{\mathrm{bg} \_416}$ (гистограмма 1 ) и областей с эритроцитами $B_{\mathrm{RBC}} / B_{\mathrm{RBC}} 416$ (гистограмма 2). Поскольку эритроциты на этом графике начинаются со значения яркости 560 , то для их идентификации было выбрано несколько меньшее значение граничного параметра $K_{1}$, равное 540. При таком значении $K_{1}$ площадь идентифицированных эритроцитов (алгоритм представлен в следующем разделе) хорошо соответствовала их действительной видимой величине.

В то же время важно отметить, что выбор граничного параметра $K_{1}$, равного 540 (рис. $5, a$ ), не совсем оправдан: эксперименты показывают, что в опытах с одним интерференционным светофильтром IF416 яркость оказывается чрезвычайно малой из-за сильного поглощения света гемоглобином. Действительно, использование одного интерференционного светофильтра „срезало“ 99.6\% начального светового потока от источ- 
Таблица 2. Экспериментальные значения (rel.units) средних яркостей фрагментов фотоизображений, содержащие фон и эритроциты, полученные без светофильтра (столбец 2), со светофильтром IF416 (столбец 3), а также с парами светофильтров IF416+C3C-23 (столбец 4) и IF620+C3C-23 (столбец 5); в столбцах 6, 7 приведены отношения указанных яркостей (в \%)

\begin{tabular}{l|c|c|c|c|c|c}
\hline $\begin{array}{c}\text { Фрагмент } \\
\text { изображения }\end{array}$ & $\begin{array}{c}\text { Без } \\
\text { фильтра }\end{array}$ & IF416 & $\begin{array}{c}\text { IF416+ } \\
\text { С3С-23 }\end{array}$ & $\begin{array}{c}\text { IF620+ } \\
\text { С3C-23 }\end{array}$ & $\begin{array}{c}\text { IF416/ } \\
\text { без фильтра, \% }\end{array}$ & $\begin{array}{c}\text { (IF416+C3C-23)/ } \\
\text { (IF620+C3C-23), \% }\end{array}$ \\
\hline 1 & 2 & 3 & 4 & 5 & 6 & 7 \\
\hline Фон & 1751 & 5 & 575 & 497 & 0.29 & 115.69 \\
$\mathrm{RBC}$ & 1624 & 2 & 381 & 499 & 0.12 & 76.35 \\
$\mathrm{RBC/фон}$ & 0.93 & 0.40 & 0.66 & 1.00 & &
\end{tabular}
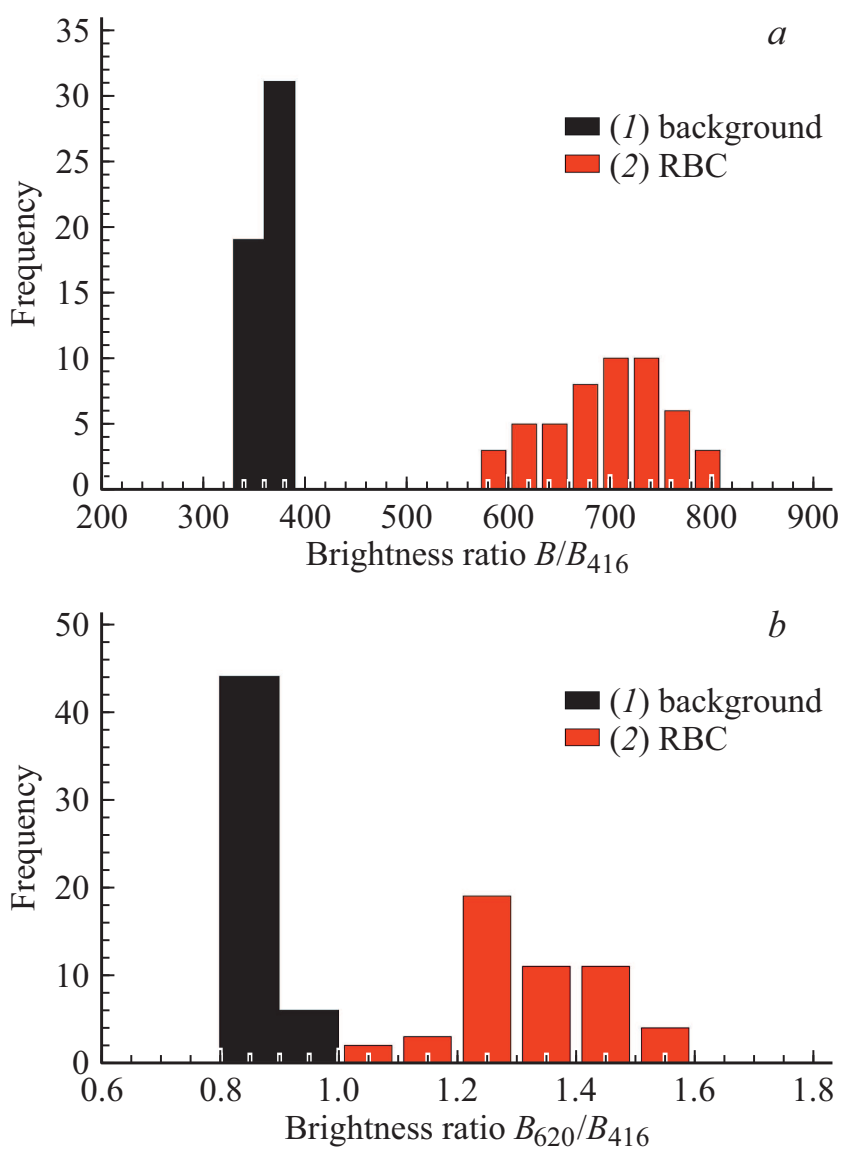

Рис. 5. Распределение отношения яркостей 50 фоновых участков фотографий (1) и 50 участков, содержащих эритроциты (2). Гистограммы, полученные для пары микрофотографий образца S1 (без светофильтра/со светофильтром IF416) (a). Гистограммы, полученные для пары микрофотографий образца S2 (со светофильтрами IF416+C3C-23) со светофильтрами IF620+C3C-23 (b).

ника. В силу этого яркость пикселей матрицы камеры в области эритроцитов составляла всего 1-2 единицы из 4096 (табл. 2). Это означает, что 1) гистограммы, приведенные на рис. 5, $a$, а следовательно, и выбранная величина $K_{1}$ не совсем надежные, 2) применение описанного метода идентификации эритроцитов является чувствительным к выбору камеры. При использовании более простой версии камеры с глубиной цвета 8 bit полученного результата достичь было бы нельзя.

Вот почему целесообразно перейти к рассмотрению экспериментов с двумя интерференционными светофильтрами IF416 и IF620, а также сине-зеленым светофильтром типа С 3 -23. В этом случае путем увеличения яркости источника света микроскопа 1) оказывается возможным увеличить яркость фотоизображений, избегая при этом эффекта „насыщения“ камеры, а следовательно, получить более точное распределение яркости по участкам фотографий, 2) выровнять световые потоки для обеих пар светофильтров (табл. 2). В результате средняя яркость в области фона на фотографиях, полученных со светофильтрами IF620+C3C-23, оказалась равной 497 и 575 - на фотографиях, полученных со светофильтрами IF416+C3C-23. Аналогичная яркость в областях эритроцитов на фотографиях, полученных со светофильтрами IF620+C3C-23, составила 499 и 381 - на фотографиях, полученных со светофильтрами IF416+C3C-23. Полученные из эксперимента средние значения яркостей областей фотографий размещены в столбцах 4 и 5 табл. 2. Предпринятые меры повысили надежность в определении граничного параметра $K_{2}$, соответствующие гистограммы отображены на рис. $5, b$. Анализ гистограмм привел к выбору граничного значения параметра $K_{2}$, равному $1 / 15$. Из рассмотренного следует, что для более точной идентификации эритроцитов целесообразно использование двух пар светофильтров IF620+C3C-23 и IF416+C3C-23.

\section{4. Алгоритм автоматизированной идентификации эритроцитов}

Для идентификации эритроцитов методом, описанным в разд. 2, важным понятием является введенное в этом разделе „относительное изображение“. Именно преобразование реальных изображений эритроцитов (рис. 4) в адекватные относительные изображения RBC с дальнейшим их анализом является основой предлагаемого метода идентификации эритроцитов. Типичное относительное изображение, нормированное на максимальное значение яркости 255, представлено на рис. 6. 


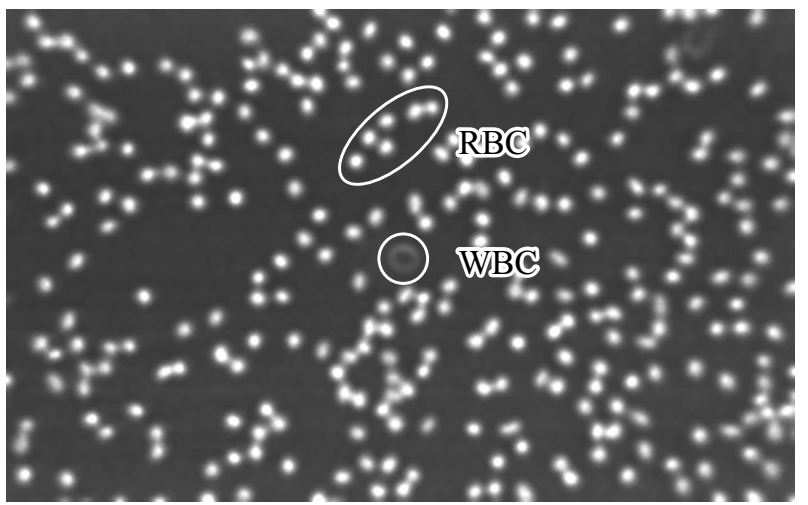

Рис. 6. Нормированное на максимальную яркость 255 относительное изображение микропрепарата с раствором нативной донорской крови S1 в физиологическом растворе (1:100).
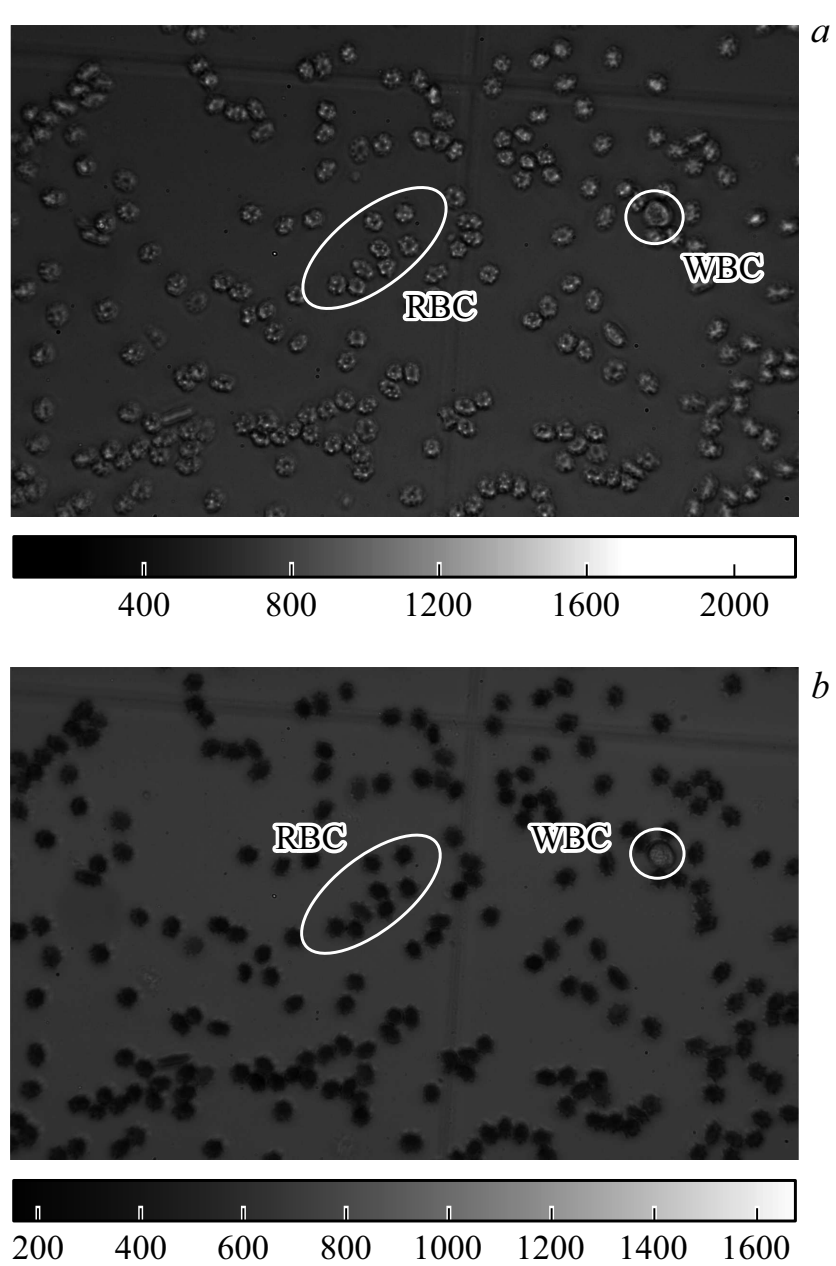

Рис. 7. Изображения микропрепарата раствора нативной донорской крови S2 в физиологическом растворе (1:100), полученные со светофильтрами IF620+C3C-23 (a), а также со светофильтрами IF416+C3C-23 (b) в канале освещения.

На данном изображении эритроциты выглядят в виде светлых пятен, размер которых коррелирует с их фактическим размером. Область, соответствующая лейкоциту на рис. 6, в отличие от рис. 4 имеет большую яркость по сравнению с фоном, но меньшую, нежели яркость эритроцитов.

Для образца крови S2 было выполнено по 10 пар фотографий для каждого разведения $(1: 100,1: 400)$ с использованием методики, описанной в разд. 2 . На рис. 7 представлены типичные микрофотографии, полученные со светофильтрами IF620+C3C-23 (a), а также со светофильтрами IF416+C3C-23 (b) в канале освещения микроскопа.

Следует обратить внимание на то, что контрастность изображения эритроцит-фон выше на рис. 7, $b$ по сравнению с рис. $4, b$.

Рассмотрим алгоритм обработки фотоизображений. При разработке программы распознания и подсчета эритроцитов на полученных микрофотографиях была использована библиотека искусственного зрения OpenCV. В качестве одного из входных параметров разработанной программы указывается разрешающая способность фотографии (pel $/ \mathrm{mm})$. Эта информация используется для того, чтобы иметь возможность вычислять действительные геометрические размеры эритроцитов непосредственно в программе. Рассмотрим алгоритм разработанной программы подробнее.

1. Загрузка двух фотографий микропрепарата. На первом этапе загружается пара фотографий раствора нативной донорской крови, соответствующих одной определенной области микропрепарата (img_0 и img_f_0). При этом фотография img_0 соответствует фотоизображению, полученному без использования светофильтров, а фотография img_f_0 - с использованием светофильтра IF416. Во втором варианте эксперимента изображение img_0 получено с парой светофильтров IF620+C3C-23, a img_f_0 - фотография, полученная c парой светофильтров IF416+CPC-23. Размер загружаемых фотографий составлял $w \times h(1920 \times 1200)$ пикселей.

2. Размытие фотографий круглой маской. Для того чтобы нивелировать на изображениях эффекты рассеяния света эритроцитами и учитывать только их поглощение, оба изображения подвергались размытию. Для этого использовалась стандартная функция filter2D библиотеки OpenCV. При этом яркость каждого пикселя фотографии усреднялась в пределах круглой области радиусом $r$, задаваемой с помощью маски. С одной стороны, радиус зоны усреднения должен быть достаточным, чтобы устранить эффекты рассеяния света и не допустить излишнего усложнения последующих этапов алгоритма. С другой стороны, при усреднении также размывается информация о поглощении, а также о краях эритроцитов, что может помешать определять их размеры правильно. Отсюда следует, что радиус зоны усреднения не может быть слишком большим. Путем подбора радиус $r$ был выбран равным $2 \mu \mathrm{m}$ и затем пересчитывался в пиксели в соответствии с разрешающей способностью фотографии. 
В результате размытия изображения img_0 было получено изображение img_blur, а результатом размытия изображения img_f_0 стало изображение img_f_blur (blur - размытие).

3. Вычисление относительного изображения. Относительное изображение img_rel получается путем поэлементного деления матриц img_blur/img_f_blur. Пример относительного изображения, нормированного на максимальную яркость 255, представлен на рис. 6.

4. Нахождение локальных максимумов яркости на относительном изображении. Как можно судить по рис. 6, эритроциты на относительном изображении имеют вид светлых пятен с нечеткими краями. Причем, как правило, одному эритроциту соответствует один локальный максимум яркости. В связи с этим следующим этапом идентификации эритроцитов стало определение координат всех локальных максимумов яркости на относительном изображении. Для выполнения этой задачи был использован алгоритм, представленный на электронном pecypce [21]. В этом методе локальные максимумы находятся в пределах области $27 \times 27$ пикселей. Другими словами, если расстояние между максимумами меньше 27, то будет оставлен только один из них, имеющий большее значение. В результате этой операции создается массив maxima, который содержит координаты всех локальных максимумов на относительном изображении.

Заметим, что не все локальные максимумы на относительном изображении соответствовали эритроцитам. Некоторые из них оказались на фоновой части изображений и были вызваны локальными шумами.

5. Бинаризация относительного изображения по пороговому значению. Этот этап в процедурах распознавания и анализа изображений является достаточно стандартным. Он заключается в том, что каждому пикселю присваивается значение либо 0, либо 255 в зависимости от его яркости $B$. Если яркость пикселя меньше порогового значения $B<K$, то ему присваивается значение 0 , а если она больше либо равна пороговому значению $B \geq K$, то пикселю присваивается значение 255. Полученное в результате этого изображение img_bin имеет два уровня яркости (0 и 255) и называется бинарным. Применение процедуры бинаризации к относительному изображению img_rel приведет к тому, что светлые области эритроцитов преобразуются в белые области, а фон и прочие форменные элементы крови образуют черный фон.

Поскольку светлые пятна эритроцитов на относительном изображении имеют размытые края, то описанная процедура бинаризации приведет к тому, что размер белых пятен эритроцитов на бинарном изображении будет меньше действительных размеров эритроцитов. Это связано с тем, что на краю эритроцитов яркость пикселей меньше порогового уровня $K$. Чтобы обойти этот эффект, процедура бинаризации была несколько изменена. Во-первых, создавался черный холст такого же размера, как и относительное изображение img_rel. После этого проводилось сканирование полученного
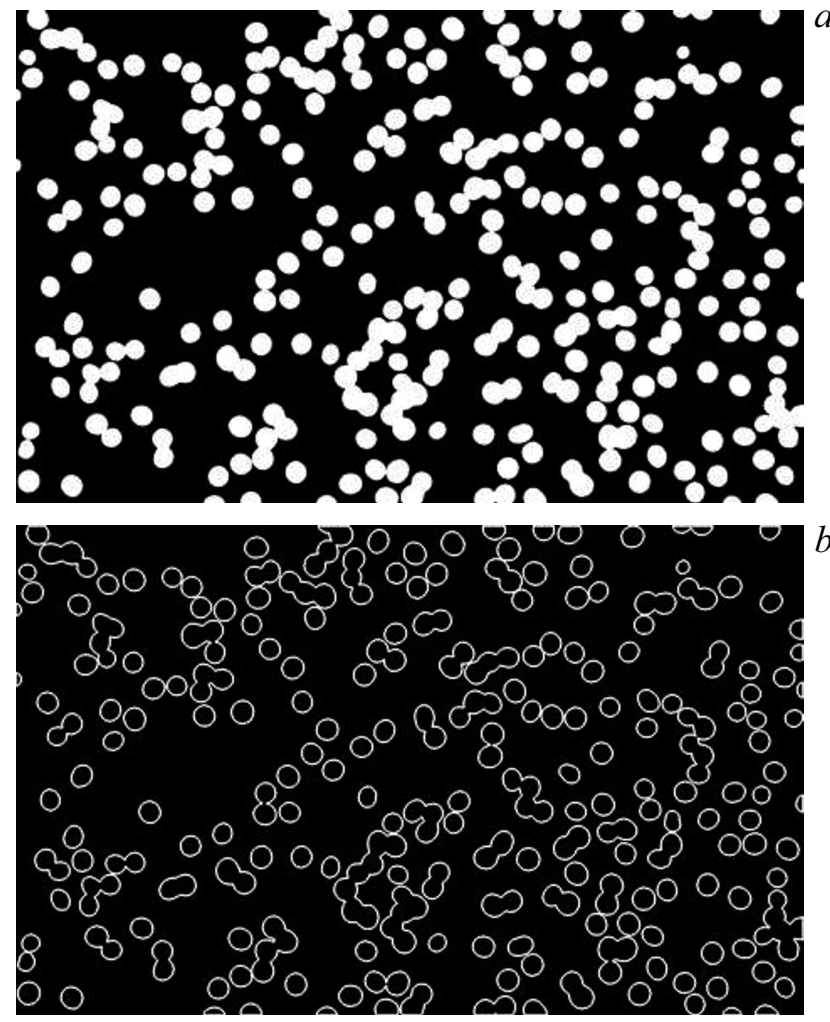

Рис. 8. Бинаризованное $(a)$ и контурное $(b)$ изображения микропрепарата с раствором нативной донорской крови S1 в физиологическом растворе (1:100).

на третьем этапе относительного изображения img_rel. Если яркость очередного пикселя $B(i, j)$ превышала пороговое значение $K$, то на черном холсте белым цветом закрашивалась соответствующая круглая область с центром в точке $(i, j)$. Радиус закрашиваемой области $r_{\text {paint }}$ был выбран таким образом, чтобы размер получаемой белой области эритроцита на бинарном изображении соответствовал наблюдаемому действительному размеру эритроцитов на оригинальном изображении img_0. В рассматриваемом алгоритме величина $r_{\text {paint }}$ была принята равной $1 \mu \mathrm{m}$ и переведена в пиксели в соответствии с разрешающей способностью фотографий.

Пороговое значение $K$ выбиралось в зависимости от используемых светофильтров и описано в предыдущем разделе. Пример полученного модифицированным способом бинарного изображения представлен на рис. 8, $a$. Как видно на данном изображении, эритроциты представлены белыми областями. Кроме того, лейкоцит, который на оригинальном изображении присутствует в центре (рис. $3, a$ ), на данном изображении отсутствует.

6. Нахождение контуров. На этом этапе программа находила контуры белых областей на бинарном изображении (рис. $8, b$ ). Эта процедура выполнялась с помощью стандартной функции findContours библиотеки OpenCV. Каждый такой контур представляет собой упорядоченную против часовой стрелки последовательность коор- 
динат границы белой области. Некоторые из найденных контуров соответствовали единичным эритроцитам, а некоторые объединяли собой по несколько эритроцитов. Результатом функции findContours был массив контуpoв — cnts_0.

Можно сказать, что на этом этапе программа „узнавала“" о существовании эритроцитов на изображении. С этого момента и далее анализу подвергались не только пиксели относительного изображения, но и найденные объекты, представленные контурами.

7. Удаление мелких контуров. Некоторые из найденных в результате прошлой операции контуров не соответствовали эритроцитам, но были вызваны наличием лейкоцитов или иных артефактов. Однако площадь таких контуров была значительно меньше контуров, соответствующих эритроцитам. Логичным шагом стала фильтрация мелких контуров по признаку площади. При этом все контуры площадью меньше $1 \mu \mathrm{m}^{2}$ отбрасывались из дальнейшего анализа с образованием нового массива контуров cnts_1.

8. Присваивание локальных максимумов контурам. В результате выполнения этапа 4 создается массив локальных максимумов, а в результате выполнения этапов 6 и 7 - массив контуров. Практически все эти контуры соответствуют эритроцитам. Тем не менее некоторые контуры соответствуют одному эритроциту, а некоторые - нескольким. Для того чтобы можно было найти количество эритроцитов внутри каждого контура, проводилась операция ассоциирования локальных максимумов, соответствующих эритроцитам, соответствующим контурам, в пределах которых эти максимумы находятся.

Эта процедура осуществляется путем перебора всех контуров cnts_1 и всех максимумов maxima с проверкой условия нахождения максимумов в пределах каждого контура. Так, если некоторый максимум находится на территории некоторого контура, то стандартная функция OpenCV - pointPolygonTest принимает значение $\geq 0$.

В результате выполнения этого этапа формировался массив структур cnts_info, каждая из которых содержала информацию о контуре, количестве максимумов в его пределах и их координатах, а также еще два элемента, о которых будет сказано дальше. Еще одним результатом этого этапа стало исключение из дальнейшего анализа тех максимумов, которые не соответствовали эритроцитам, а были на фоновой части изображения.

9. Анализ формы контуров. С целью повышения надежности распознавания эритроцитов на этом этапе анализируется форма эритроцитов, а именно количество выпуклых и вогнутых частей. В дальнейшем эта информация будет использоваться для уточнения количества эритроцитов в контурах. Как было отмечено выше, каждый контур представляет собой упорядоченную последовательность координат границы белой области бинарного изображения. Пусть некоторая точка $A$ контура имеет координаты $\left(x_{i}, y_{i}\right)(i=1,2, \ldots, n)$, где $n-$ число точек контура. Тогда некоторая следующая точка $B$ этого контура будет иметь координаты $\left(x_{i+s}, y_{i+s}\right)$, где $s$ - постоянный шаг смещения индекса. Следующая за ней с таким же шагом $s$ точка $C$ имеет координаты $\left(x_{i+2 s}, y_{i+2 s}\right)$. Направление смещения $A B$ представим в виде вектора a, а направление смещения $B C-$ в виде вектора $\mathbf{b}$.

Чтобы определить выпуклость или вогнутость рассматриваемого участка контура, достаточно найти векторное произведение $\mathbf{v}=\mathbf{a} \times \mathbf{b}$ и определить его направление. Если участок контура выпуклый, то компонента $v_{z}<0$, а если этот участок вогнутый, то $v_{z}>0$. Если векторы $\mathbf{a}$ и $\mathbf{b}$ совпадают по направлению, то $v_{z}=0$.

Общее число выпуклостей и вогнутостей вдоль контура определялось путем прохождения всех точек контура с постоянным шагом индекса $s$. При этом алгоритм учитывал, что если при последовательном смещении компонента $v_{z}$ не меняет знак, то это тот же фрагмент выпуклости или вогнутости. Оптимальный шаг $s$ был выбран равным 8. При таком шаге исключались мелкие перегибы контура, которые не несли информацию о количестве эритроцитов, но оставлялись макроперегибы, которые такую информацию отражали. В результате выполнения этого этапа описание каждого контура из массива contours_info пополняется двумя характеристиками: числом выпуклостей и числом вогнутостей.

10. Нахождение среднего размера эритроцитов. Эта операция выполняется с помощью стандартной процедуры contourArea библиотеки OpenCV. При этом анализируются только те контуры, которые удовлетворяют двум условиям. Во-первых, контур должен быть одиночным, т. е. содержать только один эритроцит. Выполнение этого условия гарантируется, если число выпуклостей контура равно 1, а вогнутых частей нет. Во-вторых, нельзя анализировать контуры на краю изображения, поскольку они могут содержать только часть эритроцита. Для выполнения второго условия из анализа исключаются контуры, центры которых находятся от краев ближе, чем $5.5 \mu \mathrm{m}$.

11. Фильтрация максимумов. Полученная на предыдущих этапах информация о максимумах яркости относительного изображения, контурах эритроцитов, их размере и форме используется, чтобы уточнить количество эритроцитов. Эта фильтрация осуществляется в несколько стадий в соответствии с проверяемым условием. При этом на каждом этапе исключается некоторое количество максимумов, чтобы в конечном счете число максимумов соответствовало количеству эритроцитов на изображении.

11.1. Анализ одно- и двухчастичных контуров. После выполнения предыдущих этапов иногда получается так, что в контуре, содержащем один эритроцит, обнаруживается больше или меньше одного локального максимума. Так, меньшее число максимумов в пределах контура бывает, например, в случаях, когда эритроцит находится на краю фотоизображения. Больше одного максимума в пределах одночастичного контура может 
быть обнаружено, если эритроцит оказывается разбухшим. С другой стороны, в контурах, содержащих два эритроцита, порой обнаруживается больше или меньше двух максимумов. Последнее возможно, если два эритроцита накладываются друг на друга на фотоизображении. После выполнения анализа формы контуров можно легко определить те из них, в которых находится один или два эритроцита, несмотря на максимумы в их пределах. Так, если контур имеет одну выпуклость и не содержит вогнутых частей, то он гарантированно содержит только один эритроцит. Такому контуру присваивается один максимум с координатами в геометрическом центре этого контура. Контур, содержащий два эритроцита, практически всегда имеет две выпуклых части и две вогнутых. Если у такого контура было обнаружено максимумов больше двух, то оставляется два из них, имеющих наибольшую амплитуду. Если в пределах такого контура обнаруживается меньше двух максимумов, то добавляются дополнительные, чтобы их количество стало равным двум.

11.2. Удаление максимумов, близких к правой и нижсней границам фотоизображсения. При ручном подсчете числа эритроцитов на изображении не учитывались те из них, которые хотя бы краем попадали на правую или нижнюю границу изображения. Одновременно с этим эритроциты, попадающие на верхний и левый края, считались. Реализация этого правила при программном подсчете заключается в том, что из контуров исключаются те максимумы, которые находятся от правой или нижней границ на расстоянии большем, чем средний радиус эритроцитов. Последняя величина находится на этапе 10 рассматриваемого алгоритма. Если оказывается так, что после удаления максимумов контур остается пустым, то он также исключается из дальнейшего анализа.

11.3. Удаление лишних максимумов из малых конmуров. Некоторые эритроциты на изображениях имеют не округлую, а выпукло-вогнутую форму (1 выпуклость и 1 вогнутость). Иногда в таких контурах определяется больше одного максимума. С другой стороны, бывают выпукло-вогнутые контуры, содержащие 2 эритроцита. Для того чтобы определить, является ли второй максимум в контуре лишним или нет, вычисляется удельная площадь эритроцита $S_{\mathrm{RBC}}=S_{\mathrm{cnt}} / n_{\max }$. В последней формуле $S_{\mathrm{cnt}}-$ площадь контура, а $n_{\max }-$ число максимумов в контуре. Если удельная площадь оказывается меньше минимальной площади одного эритроцита $S_{\mathrm{RBC}}<S_{\min }$, то в контуре оставляется только один максимум с максимальной яркостью. Путем подбора значение минимальной площади эритроцита было выбрано равным $0.6 S_{\mathrm{cp}}$, где последняя величина определяется на этапе 10 алгоритма.

11.4. Удаление близких локальных максимумов. Последний этап фильтрации связан с удалением одного из близко расположенных максимумов. Для этого выбирается минимально возможное расстояние $d_{\min }$, на котором могут находиться максимумы разных эритроцитов.

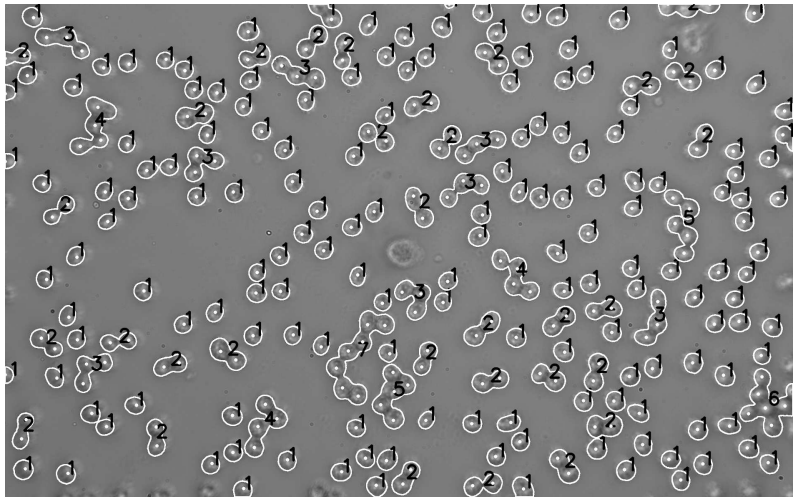

Рис. 9. Оригинальная фотография микропрепарата раствора нативной донорской крови S1 в физиологическом растворе (1:100) с нарисованными программным способом контурами распознанных эритроцитов. Точками указаны центры эритроцитов, а цифрами обозначено количество эритроцитов в каждом из контуров. Фото на рисунке соответствует фотоизображениям на рис. 4 и 6.

При этом если расстояние между двумя максимумами меньше $d_{\min }$, то удаляется менее яркий максимум. Путем подбора величина $d_{\min }$ была выбрана равной среднему радиусу эритроцитов, найденному на этапе 10 алгоритма.

12. Подсчет и сохранение числа эритроцитов. После всех вышеперечисленных этапов подсчитывается суммарное число максимумов внутри каждого контура на изображении. Это значение принимается равным количеству эритроцитов на микрофотографии.

На рис. 9 представлено оригинальное изображение микропрепарата, на котором программным способом были нарисованы все найденные контуры эритроцитов, точками указаны найденные локальные максимумы, а цифрами обозначено программно подсчитанное количество эритроцитов в пределах каждого контура. Как можно видеть, размеры и форма контуров практически совпадают с действительными размерами и формой эритроцитов, что свидетельствует об адекватности выбранного подхода. Отметим, что с помощью описанного метода можно не только осуществлять подсчет эритроцитов, но и определять их распределение по размерам. Для этого достаточно использовать информацию о площадях контуров, соответствующих одиночным эритроцитам.

\section{5. Результаты компьютерного подсчета и анализа размеров эритроцитов}

Рассмотрим результаты выполнения описанного выше алгоритма идентификации эритроцитов на микрофотографиях. В первую очередь оценим точность идентификации эритроцитов путем сравнения числа эритроцитов, посчитанных разработанной программой, с числом таковых, посчитанных „вручную“ путем визуального наблюдения клеток на фотографиях. Заметим, что на каждой 
Таблица 3. Доля программно распознанных эритроцитов на микрофотографиях раствора нативной донорской крови S1 и S2 в зависимости от степени разведения физиологическим раствором

\begin{tabular}{|c|c|c|c|c|}
\hline \multirow{3}{*}{$\begin{array}{c}\text { Степень } \\
\text { разведения }\end{array}$} & \multicolumn{2}{|c|}{ Образец S1 } & \multicolumn{2}{|c|}{ Образец S2 } \\
\hline & \multicolumn{2}{|c|}{ (без светофильтра/IF416) } & \multicolumn{2}{|c|}{$(\mathrm{IF} 620+\mathrm{C} 3 \mathrm{C}-23) /(\mathrm{IF} 416+\mathrm{C} 3 \mathrm{C}-23)$} \\
\hline & $\begin{array}{c}\text { Доля распознанных } \\
\text { эритрцитов, \% }\end{array}$ & $\begin{array}{c}\text { Стандартное } \\
\text { отклонение, \% }\end{array}$ & $\begin{array}{c}\text { Доля распознанных } \\
\text { эритрцитов, \% }\end{array}$ & $\begin{array}{c}\text { Стандартное } \\
\text { отклонение, \% }\end{array}$ \\
\hline $1: 100$ & 97.7 & 1.0 & 98.2 & 1.7 \\
\hline $1: 200$ & 97.8 & 1.4 & - & - \\
\hline $1: 300$ & 97.5 & 1.6 & - & - \\
\hline $1: 400$ & 97.9 & 1.4 & 102.1 & 3.8 \\
\hline
\end{tabular}

Таблица 4. Распределение нераспознанных или ложно распознанных эритроцитов на микрофотографиях нативной донорской крови S1 и S2 в зависимости от степени разведения и типа ошибки

\begin{tabular}{|c|c|c|c|c|c|c|}
\hline \multirow{3}{*}{$\begin{array}{c}\text { Степень } \\
\text { разведения }\end{array}$} & \multicolumn{3}{|c|}{ Образец S1 } & \multicolumn{3}{|c|}{ Образец S2 } \\
\hline & \multicolumn{3}{|c|}{ (без светофильтра/IF416) } & \multicolumn{3}{|c|}{$(\mathrm{IF} 620+\mathrm{C} 3 \mathrm{C}-23) /(\mathrm{IF} 416+\mathrm{C} 3 \mathrm{C}-23)$} \\
\hline & $\begin{array}{c}\text { Край } \\
\text { фотографии, \% }\end{array}$ & $\begin{array}{c}\text { Малая } \\
\text { яркость, \% }\end{array}$ & $\begin{array}{l}\text { Нераспознанный или } \\
\text { ложный эритроцит, \% }\end{array}$ & $\begin{array}{c}\text { Край } \\
\text { фотографии, \% }\end{array}$ & $\begin{array}{c}\text { Малая } \\
\text { яркость, \% }\end{array}$ & $\begin{array}{l}\text { Нераспознанный или } \\
\text { ложный эритроцит, \% }\end{array}$ \\
\hline $1: 100$ & 1.4 & 0.2 & 0.7 & 0.4 & 0 & 2.3 \\
\hline $1: 200$ & 1.7 & 0.0 & 0.5 & - & - & - \\
\hline $1: 300$ & 1.6 & 0.2 & 0.7 & - & - & - \\
\hline $1: 400$ & 1.5 & 0.0 & 0.6 & 1.7 & 0 & 2.7 \\
\hline
\end{tabular}

фотографии, на которой присутствовали лейкоциты, они не распознавались программным образом и потому не вносили погрешности в результаты счета эритроцитов.

В табл. 3 представлены данные о точности идентификации эритроцитов для образцов S1 и S2 в зависимости от степени разведения крови физиологическим раствором.

Как видно, степень разведения крови физиологическим раствором практически не влияет на точность распознавания эритроцитов, которая для образца S1 составила в среднем $97.7 \pm 1.4 \%$. Для образца $\mathrm{S} 2$, рассматриваемого с помощью двух пар светофильтров, при разведении 1:400 число распознанных эритроцитов оказалось выше их действительного количества. Этот факт вызван тем, что эритроциты в этом эксперименте оказались деформированными и на относительном изображении зачастую давали больше одного максимума, лишние максимумы полностью отфильтровать не удалось.

Для того чтобы лучшим образом оценить влияние степени разведения, а также особенностей алгоритма на точность подсчета эритроцитов, источники погрешностей были распределены на три группы (табл. 4). Первая группа нераспознанных эритроцитов (рис. 10, легенда 1) связана с тем, что многие эритроциты попали на край изображения и не были „замечены“ программой. Для образца S1 этот тип ошибки является наиболее существенным и составляет $1.4-1.7 \%$ от общего числа эритроцитов. В то же время для образца S2 эта ошибка составляет $0.4-1.7 \%$. Отметим, что ошибка распознавания эритроцитов, связанная с их краевым расположением на фотографии, может быть сведена к минимуму путем сканирования большей области микропрепарата и объединения нескольких микрофотографий в один виртуальный слайд. Другими словами, данная проблема решается техническими средствами.

Вторая группа ошибок в распознании эритроцитов (рис. 10, легенда 2) связана с тем, что некоторые эритроциты не дали достаточной амплитуды яркости на относительном изображении img_rel и оказались ниже порогового уровня бинаризации $K$, а значит, и не были распознаны. Причин недостаточности амплитуды яркости несколько. Во-первых, на краю изображения частицы оказываются не в фокусе объектива, и их изображение становится размытым. Понятно, что при этом размазывается по площади и их спектральная информация, а значит, амплитуда относительной яркости становится меньше. Кроме того, если эритроцит еще и сам по себе небольшой, то этих факторов оказывается достаточно, чтобы уровень его яркости на относительном изображении img_rel оказался ниже порогового уровня, и эритроцит остался нераспознанным. Данную проблему можно частично устранить путем использования в микроскопе планарных объективов, которые будут давать четкое изображение форменных элементов в пределах всего поля зрения.

Наконец, последняя группа ошибок распознавания эритроцитов связана с самим алгоритмом их иденти- 


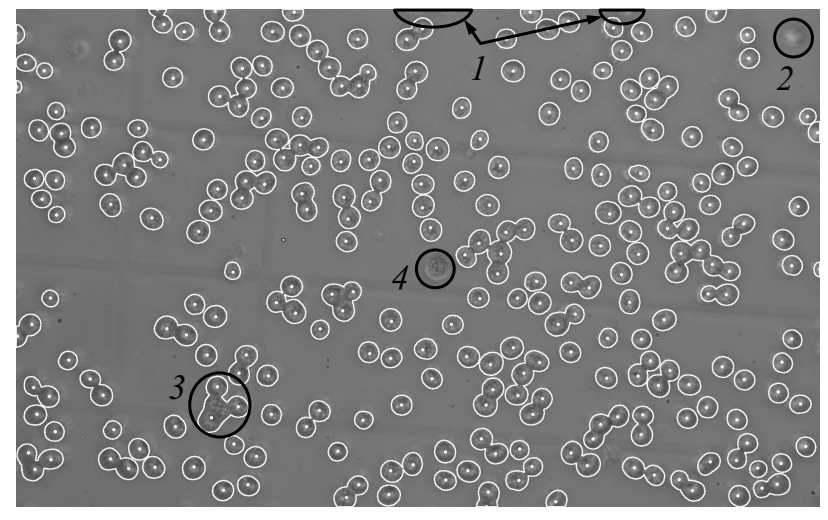

Рис. 10. Примеры неидентифицированных эритроцитов донорской крови S1 в физиологическом растворе (1:100): 1 нераспознанные эритроциты на краю изображения, 2 - эритроцит пропущен на этапе бинаризации из-за недостаточной амплитуды яркости на относительном изображении img_rel, 3 - центральный эритроцит в группе не учтен по причине отсутствия локального максимума в соответствующей области относительного изображения img_rel, 4 - лейкоцит.

фикации. Так, в некоторых контурах программа либо находила лишние эритроциты, либо находила меньшее их число. Как видно по данным табл. 4, доля этой ошибки для образца S1 составила в $0.5-0.7 \%$, а для образца S2 - 2.3-2.7\%. Отметим, что большинство нераспознанных и ложных эритроцитов было зафиксировано в контурах, соответствующих трем и более эритроцитам. Поскольку крупные группы эритроцитов наблюдались в основном при степени разведения крови 1:100, то предпочтительнее использовать большие степени разведения (1:200, 1:300, 1:400).

\section{6. Обсуждение}

В отличие от большинства работ, посвященных автоматизированному подсчету и анализу эритроцитов крови человека средствами оптической микроскопии и алгоритмов искусственного зрения, в настоящей работе нами был использован раствор нативной крови, а не окрашенный мазок. Такой подход позволяет определять концентрационные характеристики клеток крови, которые в случае использования мазка теряются. Кроме того, для непосредственной идентификации эритроцитов были использованы не особенности их морфологии (строения), но фундаментальный физический признак, связанный с составом эритроцитов, а именно наличие сильного поглощения гемоглобина в области полосы Соре. Такой подход позволил получить точность идентификации красных клеток на уровне 97-98\%, что не уступает лучшим из результатов аналогичных работ других авторов. Более того, такая точность соответствует степени надежности современных серийно выпускаемых проточных гемоанализаторов. Отметим также, что циф- ровой световой микроскоп с технической точки зрения гораздо проще, чем проточный гемоанализатор.

\section{Выводы}

Регистрация эритроцитов в нативной крови с использованием разработанного метода спектральной цифровой микроскопии обладает как относительной инструментальной простотой по сравнению с проточной гемоцитометрией, так и достаточно высокой точностью распознавания, составляющей 97\%. Кроме того, пробоподготовка с использованием нативной крови позволяет определять концентрацию эритроцитов в пробах крови, что недоступно при анализе мазков. Заметим, что технически подготовка мазков более сложная процедура, нежели подготовка раствора нативной крови, особенно если учесть необходимость достижения идентичности в окрашивании мазков, что требуется для компьютерной обработки фотоизображений мазков. Сравнение концентрации эритроцитов в крови, найденной с помощью метода, представленного в данной работе, с концентрацией, полученной с помощью гемоанализатора Sysmex XS 1000i, показывает величину отличия всего на $3 \%$. Заметим, что предложенное в работе фотографирование образцов нативной крови с использованием двух интерференционных светофильтров позволяет реализовать идентификацию и счет эритроцитов с более простой камерой, имеющей глубину цвета порядка 8 bit.

\section{Соблюдение этических стандартов}

Настоящая статья не содержит каких-либо исследований с участием людей в качестве объектов исследований.

\section{Конфликт интересов}

Авторы заявляют, что у них нет конфликта интересов.

\section{Список литературы}

[1] Новикова И.А., Ходулаева С.А. Клиническая и лабораторная гематология: учеб. пособие. Минск: Изд-во „Высшая школа“, 2013. 446 с.

[2] Шибанов А.Н., Дылдин Д.Р. Выбираем гематологический анализатор. [Электронный ресурс] Режим доступа: http://unimedao.ru/articles/6826/9671/item/88

[3] Samsel L., McCoy J.P. // J. Immun. Meth. 2015. V. 423. P. 52. doi 10.1016/j.jim.2015.03.019

[4] Kihm A., Kaestner L., Wagner C., Quint S. // PLOS Comp. Biol. 2018. V. 14. N 6. P. 15.

[5] Козинеи Г.И., Погорелов В.М. Клетки крови и современные технологии их анализа. Изд-во „Триада-Фарм“, 2002. $534 \mathrm{c}$.

[6] Комбайны микроскопии Мекос. [Электронный ресурс] Режим доступа: https://www.mecos.ru/products

[7] Shrikrishna U. Kolhar // Int. J. Adv. Res. Electr. Electron. Instrum. Engin. 2015. V. 4. N 1. P. 128. 
[8] Akshaya P. Sahastrabuddhe // Int. J. Res. Engineer. Technol. 2016. V. 5. N 5. P. 356.

[9] Razali Tomaria, Wan Nurshazwani, Wan Zakariaa // Proc. Comp. Sci. 2014. V. 42. P. 206.

[10] Hemant Tulsani, Saransh Saxena, Naveen Yadav // Int. J. Comp. Appl. Inform. Technol. 2013. V. 2. P. 28.

[11] Keyvan Jaferzadeh., Inkyu Moon // J. Biomed. Opt. 2016. V. 21. N 12. P. 1.

[12] Sumeet Chourasiya // Int. J. Comp. Sci. Inform. Technol. 2014. V. 5. N 4. P. 4834.

[13] Alaa Hamouda, Ahmed Y. Khedr, Rabie A. Ramadan // Int. J. Comp. Sci. 2012. V. 1. N 2. P. 13.

[14] Дырнаев А.В. // Научно-технический вестник СанктПетербургского государственного университета информационных технологий, механики и оптики. 2011. № 6 (76). C. 17.

[15] Yazan M. Alomari, Raja Zaharatul Azma, Khairuddin Omar // Comp. Math. Meth. Med. 2014. V. 2014. P. 1.

[16] Дубровский В.А., Торбин С.О. // Изв. Саратовского ун-та. Сер. Физика. 2017. Т. 17. № 3. С. 191.

[17] Sanu Susan Jacob, Keerthana Prasad, Pragna Rao // Frontiers in Physiology. 2019. V. 10. N 1230. Р. 1.

[18] Кугейко М.М., Смунев Д.А. // Докл. БГУИР. 2016. № 7 (101). C. 248.

[19] Optical Absorption of Hemoglobin. [Электронный ресурс] Режим доступа: https://omlc.org/spectra/hemoglobin/

[20] Дубровский В.А., Забенков И.В., Торбин С.О. // Медицинская техника. 2013. № 3 (279). С. 14.

[21] Finding Local Brightness Maximas with OpenCV. [Электронный ресурс] Режим доступа:

https://dsp.stackexchange.com/questions/17932/finding-

local-brightness-maximas-with-opencv 